\title{
Realism of confidence in sensory discrimination
}

\author{
JOSEPH V. BARANSKI \\ Defence and Civil Institute of Environmental Medicine, Toronto, Ontario, Canada \\ and \\ WILLIAM M. PETRUSIC \\ Carleton University, Ottawa, Ontario, Canada
}

\begin{abstract}
Is there a common and general basis for confidence in human judgment? Recently, we found that the properties of confidence judgments in the sensory domain mirror those previously established in the cognitive domain; notably, we found underconfidence on easy sensory judgments and overconfidence on hard sensory judgments. In contrast, data from the Uppsala laboratory in Sweden suggest that sensory judgments are unique; they found a pervasive underconfidence bias, with overconfidence being evident only on very hard sensory judgments. Olsson and Winman (1996) attempted to resolve the debate on the basis of methodological issues related to features of the stimulus display in a visual discrimination task. A reanalysis of the data reported in Baranski and Petrusic (1994), together with the findings of a new experiment that controlled stimulus display characteristics, supports the position that the difference between the Canadian and the Swedish data is real and, thus, may reflect cross-national differences in confidence in sensory discrimination.
\end{abstract}

We feel sure, our expectation becomes conviction, long before we have the objective right to be anything more than moderately expectant. (Titchener, 1905, pp. 53-55)

Contemporary students of confidence in human judgment should find Titchener's assertion both curious and intriguing. We should find it curious because there was actually very little data at the time that bore directly on the issue of whether people are good assessors of their own judgments and capabilities. Moreover, the data that did exist-which were almost exclusively psychophysicalwere not entirely supportive of his claim. If anything, the available data suggested that the relation between degree of certainty and overt judgmental accuracy is largely an individual matter:

The degree of confidence in the perception of intensive differences varies greatly for individuals, the proportion of wrong judgments of which observers were confident ranging from $1 / 3$ to $1 / 50$. The probability of correctness when confident was for most observers from .8 to .9. (Griffing, 1895, p. 85 )

Portions of this paper were reported at the 37th Annual Meeting of the Psychonomic Society, November 1996, Chicago. This research was funded in part by a grant from the Natural Sciences and Engineering Research Council of Canada. We thank Lester Krueger, Henrik Olsson, and the reviewers for their helpful comments. Correspondence concerning this article should be addressed to J. V. Baranski, Information Processing Sector, Defence and Civil Institute of Environmental Medicine, 1133 Sheppard Avenue West, P. O. Box 2000, Toronto, ON, M3M 3B9 Canada (e-mail: joe.baranski@dciem.dnd.ca) or to W. M. Petrusic, Department of Psychology, Carleton University, Ottawa, ON, K1S 5B6 Canada (e-mail: bill_petrusic@carleton.ca).
Some observers are not confident unless they are, in fact, right; while others are often confident when they are wrong. (Fullerton \& Cattell, 1892)

Soon thereafter, Henmon (1911) reached a similar conclusion:

It is evident that in spite of the instructions the various degrees of confidence come in the course of the experiment to have very different values. Some subjects are nearly always perfectly confident, while others are very cautious, e.g., a (certain) was used 90.4 per cent of the time by ( $s u b$ ject) $\mathrm{D}$ and 9.3 per cent by $\mathrm{H}$. Subject B gave no $d$ (guess) judgments at all and subjects $D, E$ and $F$ rarely gave either $c$ or $d$ judgments. (p. 199, parenthetical statements added for clarification)

Although we may never know the basis for Titchener's (1905) decree, many today will agree that, in certain circumstances, his proclamation has turned out to be remarkably prophetic. For example, in contemporary research on the calibration or realism of confidence, a person is considered overconfident (underconfident) if his or her mean confidence, $\mathrm{C}$, expressed as a percentage, exceeds (underestimates) his or her mean percentage correct, $\mathrm{P}(\mathrm{c})$, on a judgmental task. Indeed, an astounding number of studies over the past two decades have shown that people do have a tendency to overestimate the accuracy of their judgments, particularly when the judgments are difficult and, thus, the proportion of correct responses is low (for reviews of various portions of this literature, see Harvey, 1994; Keren, 1991: Lichtenstein, Fischhoff, \& Phillips, 1982; Wallsten \& Budescu, 1983; Yates, 1990). On the other hand, when judgments are relatively easy, underconfidence is often observed. This 
interaction between judgment difficulty and under/overconfidence was first brought to the attention of calibration researchers by Lichtenstein and Fischhoff (1977) and is now commonly referred to as the difficulty effect (Griffin \& Tversky, 1992) or the hard-easy effect (Gigerenzer, Hoffrage, \& Kleinbölting, 1991; for recent reviews of data and theory on the hard-easy effect, see Harvey, 1997; McClelland \& Bolger, 1994; Suantak, Bolger, \& Ferrell, 1996).

To date, the hard-easy effect and the phenomenon of overconfidence have been studied primarily in the context of cognitive judgments (e.g., general knowledge questions). In this task domain, there is a consensus that the transition from over- to underconfidence occurs at approximately $75 \%$ correct responses $^{1}$ (see the metaanalysis of over 100 studies by Suantak et al., 1996; and cf. Juslin, Olsson, \& Björkman, 1997). Interestingly, the one judgment domain in which there exists a distinct lack of consensus concerning the realism of confidence is sensory discrimination-that is, the nascent forum for the study of confidence in human judgment. Although several early studies did consider the similarities and differences between confidence in the cognitive domain and confidence in the sensory domain (Dawes, 1980; Keren, 1988; cf. Trow, 1923, for the landmark study), the empirical status of the hard-easy effect and overconfidence in sensory discrimination remained unresolved. For example, Dawes found some evidence for overconfidence in some of his perceptual tasks (Experiments 4 and 5), but Keren (1988) did not.

More recently, two papers appeared in this journal at approximately the same time, each addressing the issue of confidence calibration in sensory discrimination, but with very different data and theoretical implications. First, Björkman, Juslin, and Winman (1993), from Uppsala University in Sweden, presented data that suggested a "pervasive underconfidence bias in sensory discrimination" (p. 75). Moreover, they claimed that "psychophysical discrimination does not exhibit any hard-easy effect" (p. 79), and thus, there exists "a different nature of confidence in sensory judgments, relative to cognitive judgments" (p. 81). In support of this prediction, Björkman et al. found a consistent level of underconfidence $(11 \%-$ $14 \%$ ) for tasks in which judgment accuracy ranged between $67 \%$ and $88 \%$. In contrast, Baranski and Petrusic (1994), from Carleton University in Canada, presented data from three experiments that demonstrated that "overconfidence can be obtained in a perceptual task when judgments are difficult enough to produce a substantial decrease in accuracy" (p. 423) and, consequently, that "there appears to be a common and general process for evaluating probabilistic information, obtaining a feeling of certainty in a judgment, and transforming that feeling into a numerical probability estimate" (p. 424).

Since the publication of the two papers, the members of the Uppsala group have provided additional evidence that sensory discrimination is characterized by underconfidence (e.g., Winman \& Juslin, 1993). More recently,
Juslin and Olsson (1997) provided a model of confidence calibration in sensory discrimination that predicts a hardeasy effect, although the predicted nature of the hardeasy effect in the sensory domain is fundamentally different from that typically observed in the cognitive domain. For example, the model can predict overconfidence in sensory discrimination, but only when judgments are (1) time pressured (see, e.g., Baranski \& Petrusic, 1994, Experiment 1), (2) subject to large perceptual biases, and (3) extremely difficult. As an example of empirical support for the latter prediction, Juslin and Olsson (1997, Experiment 1) provided data from a line length comparison task, in which overconfidence was evident only in the limited case of no discriminability (i.e., the two lines were the same length) and, thus, responding was at a chance level (i.e., $50 \%$ correct): "There is underconfidence for all stimulus units, except the unit with zero difference where there is overconfidence. ... The sensory sampling model predicts this extreme underconfidence bias" (Juslin \& Olsson, 1997, p. 358).

In contrast to the data reported by the Uppsala laboratory and the predictions of their sensory-sampling model, we have reported several studies in which the pattern of the hard-easy effect in sensory discrimination paralleled that often observed in the cognitive domain (Aubin \& Petrusic, 1997; Baranski \& Petrusic, 1988, 1995, 1998; Petrusic \& Baranski, 1997). Importantly, in each of those demonstrations, the sensory judgments were not biased, the subjects were not time pressured, and the stimuli were not indistinguishable. Understandably, this difference in the data on the realism of confidence in sensory discrimination has been manifested in a clear divergence in theoretical direction. We have advocated the investigation and development of broad classes of decision and confidence models, such as those rooted in signal detection theory (Ferrell, 1994, 1995; Ferrell \& McGoey, 1980), in stochastic-latency mechanisms, such as accumulator processes (see, e.g., Audley, 1960; Baranski \& Petrusic, 1991, 1996, 1998; Petrusic \& Baranski, 1997; Vickers, 1979; Vickers \& Packer, 1982; Vickers, Smith, Burt, \& Brown, 1985) and random walks (e.g., Heath, 1985; Link, 1992), or in very general judgmental error mechanisms (Erev, Wallsten, \& Budescu, 1994). The Uppsala group, on the other hand, has advocated and developed distinct models of judgment and confidence in the cognitive (knowledge) domain (Björkman, 1994; Juslin, 1993, 1994; Juslin et al., 1997), as opposed to the sensory domain (Björkman et al., 1993; Juslin \& Olsson, 1997; Winman \& Juslin, 1993).

\section{Olsson and Winman (1996)}

In a recent paper in this journal, Olsson and Winman (1996; henceforth, O\&W) provided a direct challenge to Baranski and Petrusic's (1994) data on methodological grounds. In particular, they focused on our second experiment, which involved comparisons of horizontal (visual) locations. (A schematic representation of the task in provided in Figure 1.) The task requires observers to decide 


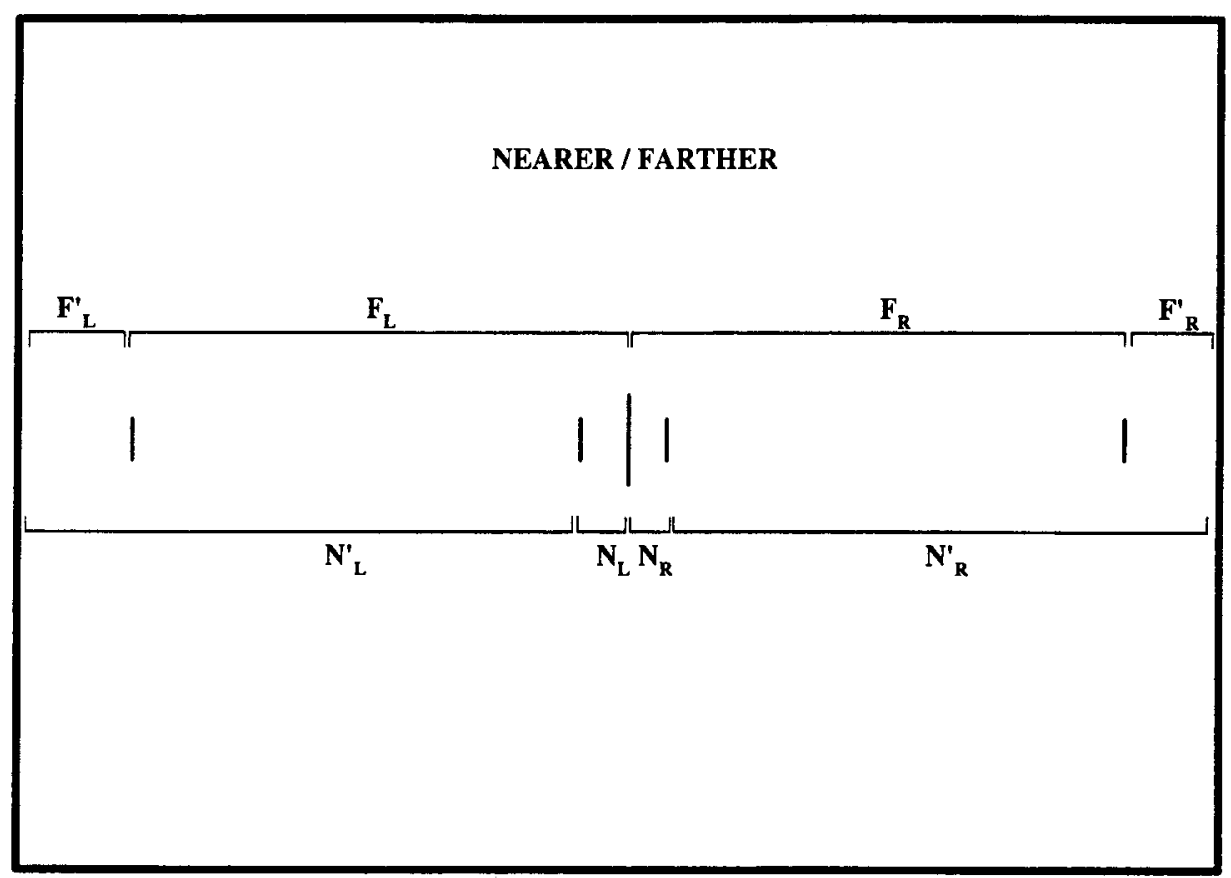

Figure 1. Schematic representation of the display used in Baranski and Petrusic (1994, Experiment 2). Comparison pairs are denoted by the distances between the left and right stimuli and the referent. For example, the pair $N_{L}, N_{R}$ denotes a comparison pair in which the stimuli are relatively near to the referent and the pair $F_{L}, F_{R}$ denotes a pair in which the stimuli are relatively far from the referent. Distances $F_{L}^{\prime}, F_{R}^{\prime}, N_{L}^{\prime}$, and $N_{R}^{\prime}$ denote distances between the stimuli and the edge of the computer video monitor.

which of two 5-mm vertical lines, one on either side, is nearer or farther from a 10 -mm vertical referent line and then to provide a subjective probability-confidence rating to denote the degree of certainty in the correctness of their judgment. Our experiment included six pairs: three that were relatively near to the referent (e.g., $N_{L}, N_{R}$ ) and three that were relatively far from the referent (e.g., $F_{L}, F_{R}$ ). In addition, for both the near and the far pairs, we varied the difficulty of the comparisons by varying the ratio of the distances between the referent and the comparison stimuli (1.07, easy; 1.04, moderate; 1.01 , hard). Our data revealed two principal findings. First, there was a transition from under- to overconfidence as judgment difficulty increased-that is, the hard-easy effect. Second, we found that discriminative accuracy depended on the order in which the comparison stimuli were presented, and we referred to this finding as a positional-order effect, which is a variant of the classical Fechnerian (1860/ 1966) space error. ${ }^{2}$

In the particular manifestation of the space error observed in our 1994 study, judgments were more accurate when the stimulus on the left was farther from the referent. For example, for the difficult comparison pair that was near to the referent, the subjects were $67.3 \%$ correct in the order 70,69 (where 70 [69] denotes the distance in pixels from the referent to the left [right] stimulus); on the other hand, the subjects were $55.1 \%$ correct in the order
69,70 . Importantly, the subjects displayed moderate overconfidence in both of these presentation orders. For the difficult pair that was far from the referent, the space error was even larger; the subjects were $87.1 \%$ correct in the order 300,296 and showed underconfidence, but were only $25.5 \%$ correct in the order 296,300 and, thus, showed dramatic overconfidence. Hence, in the latter configuration, the space error was large enough to be illusory in the compromised order [i.e., $\mathrm{P}(\mathrm{c})<50 \%$ ]

O\&W (1996) argued that our 1994 finding of overconfidence and the hard-easy effect can be accounted for if two conditions were true: (1) Our subjects were using the edge of the computer screen as an aid in making their comparative judgments; for example, for the far pairs, instead of judging the distances $F_{L}$ and $F_{R}$, the subjects were judging the shorter distances $F_{L}^{\prime}$ and $F_{R}^{\prime}$ (see Figure 1), which, as O\&W correctly pointed out, led to a higher ratio of the two extents and, thus, to an easier judgment; and (2) we employed a misaligned computer screen that misled subjects who were using the edge strategy under the assumption that the referent was placed exactly in the center of the screen. They then showed, in their first experiment, that by deliberately misaligning the stimulus display, they could reproduce the pattern of findings we obtained, could reverse it, and, in their control condition, in which the display and referent were perfectly centered, could obtain underconfidence. In their second 
experiment, involving very difficult comparisons and a display mask that precluded the use of the edge of the monitor, they found no space error and no overconfidence.

Thus, O\&W's (1996) main points were that subjects find the task easier using an edge strategy, that our subjects must have used an edge strategy, and, consequently, that our demonstration of overconfidence was a methodological artifact. Subsequently, the members of the Uppsala laboratory have promulgated this contention in recent publications (Juslin \& Olsson, 1997) and in international forums (Juslin \& Olsson, 1996).

\section{The Present Study}

The present paper has three parts. First, we provide a reanalysis of our 1994 data that will demonstrate that systematic manipulation of the display need not affect the space error in the manner postulated by O\&W (1996). Second, we provide empirical evidence from a new task that a robust hard-easy effect and clear overconfidence can be obtained under experimental conditions that preclude the use of the edge of the screen. Finally, we conclude the paper with some hypotheses concerning the discrepancy between our data and the data emanating from the Uppsala laboratory.

\section{DISPLAY MANIPULATION AND THE EDGE STRATEGY A Reanalysis of Baranski and Petrusic (1994, Experiment 2)}

The O\&W (1996) hypothesis is developed under the assumption that we were unaware of the possibility that subjects might use the edge of the screen as an aid in making their judgments. In fact, in all of our experiments employing the near-far task, we have been acutely aware that subjects might use the edge strategy, especially with the far pairs (see Petrusic, 1992; Petrusic \& Baranski, $1989 \mathrm{a}, 1989 \mathrm{~b}, 1997)$. Indeed, precisely in order to preclude the use of the edge of the screen,

All subjects were told that because the fixation point varied from trial to trial (sometimes to the left of center, sometimes to the right), the edge of the screen did not provide a reliable cue for the nearer-farther judgment. (Petrusic, 1992, p. 975)

The central marker was presented equally often either bisecting the screen or 2 pixels to the left or right of the center of the screen. The three levels of this nuisance factor ensured that the subjects performed the comparison in relation to the referent and did not rely on estimates of the distance from the edge of the video monitor. (Petrusic \& Baranski, 1989a)

In our 1994 study, the display was, in fact, never at the center of the screen; it was presented either 2 pixels to the left or 2 pixels to the right of center. This 4-pixel difference corresponds to approximately half of the differ- ence between O\&W's (1996) control and left/right manipulation. Accordingly, we can perform a test of the O\&W hypothesis. If their conjecture is correct, the direction of the space error reported in our study should be reversed in the two stimulus display locations, precisely as was demonstrated by O\&W through purposeful stimulus misalignment (see their Figure 3); at the very least, the magnitude and direction of the space error should be dramatically different at the two stimulus display locations.

Figure 2 provides calibration curves and summary statistics for the two presentation orders of the difficult far and near comparison pairs. These curves are obtained by plotting the percentage of correct responses associated with each level of confidence. In this way, overconfidence (underconfidence) is denoted by points falling below (above) the solid ideal calibration line. The critical result is that, in both cases (far, near), the direction of the space error is invariant over the two positions of the stimulus display. Note specifically that, for the far pair, we see the dramatic difference in performance over the two presentation orders but no difference between the two positions of the display. This leads to a major point of our 1994 study that was apparently misunderstood by O\&W (1996). They state, "Obviously, given a proportion correct of .25 and a scale that begins with $50 \%$, the subjects do not even stand a chance of not being overconfident" (p. 380). With direct reference to this result, we stated explicitly on p. 424 of our 1994 paper that the massive overconfidence with the difficult far pair is analogous to the massive overconfidence that is evident with illusory (less than chance level) general knowledge questions (see, e.g., Baranski \& Petrusic, 1995; Juslin, 1993, 1994; May, 1986), and that particular result was reported for the specific purpose of demonstrating this commonality of judgment and confidence in the sensory and cognitive domains. The critical point was that reliable overconfidence was evident for the difficult near pair in both presentation orders, where judgment accuracy was clearly above chance responding in both orders, and, following O\&W's own reasoning, it would make no sense to use the edge of the screen; that is, subjects should never use the edge of the screen for the near pair, because the ratio is 1.014 when comparison is made with respect to the referent but is a virtually impossible ratio of 1.003 when comparison is made with respect to the edge of the screen.

In sum, O\&W (1996) provided clear evidence that manipulation of the video display can produce biased judgment conditions and, thus, overconfidence. However, a reanalysis has shown that the subjects in our 1994 paper were not being misled in the manner claimed and demonstrated by O\&W. In addition, Petrusic and Baranski (1997) provide a perfect replication of clear overconfidence in both presentation orders of the difficult near pair and of invariance of the space error for all pairs upon systematic variation of the display in the near-far task. 


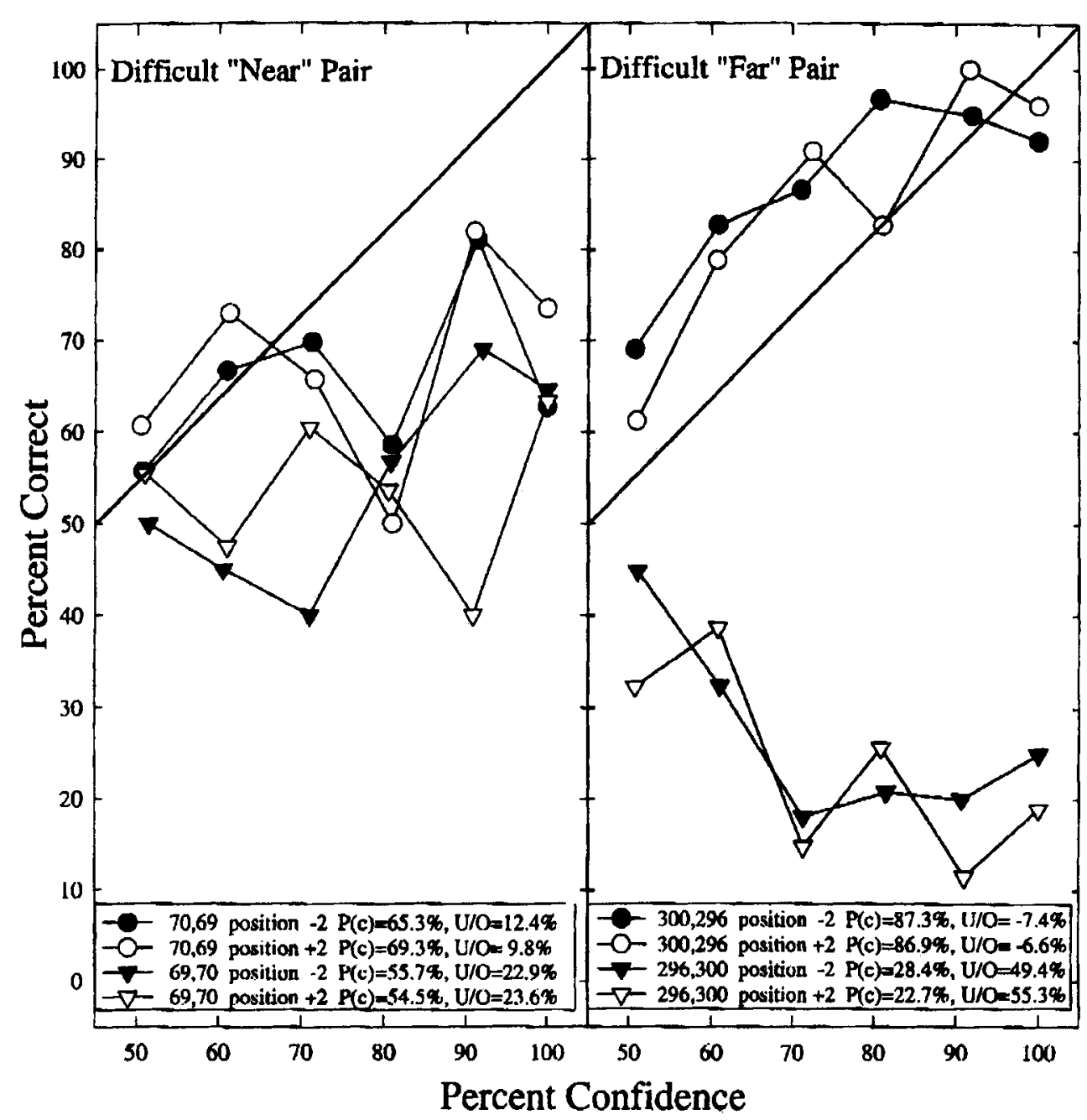

Figure 2. Reanalysis of Baranski and Petrusic (1994, Experiment 2). Left panel: Calibration curves for the difficult near pair in the two presentation orders and at the two display locations $(-2$ and +2 denotes displacement of the stimulus display by 2 pixels to the left and to the right of center, respectively). Here, calibration is invariant over referent location, and there is overconfidence in the two presentation orders. Right panel: Calibration curves for the difficult far pair. Again, calibration depends on presentation order, but, contrary to Olsson and Winman (1996), calibration is invariant over referent location. $P(c), \%$ correct responses; $\mathrm{U} / \mathrm{O}, \%$ under$/$ overconfidence $=\%$ confidence $-\%$ correct.

\section{EXPERIMENT}

Taken together, these demonstrations challenge the O\&W (1996) argument that our evidence for overconfidence was a methodological artifact. Nevertheless, it is clear that the near-far task (i.e., spatial location judgments) is, for various reasons, vulnerable to sizable space errors, and thus it is important to confirm our findings of overconfidence in sensory discrimination in a task domain that may be less vulnerable to these space errors. Accordingly, the present study employed a modern (computerbased) version of the classic horizontal line length comparison task that was used in the pioneering studies of confidence in sensory discrimination (Festinger, 1943; Garrett, 1922; Henmon, 1911; Johnson, 1939; Trow, 1923). In addition, we followed the $O \& W$ procedure of obscuring the edge of the video monitor and carefully measuring the stimuli directly on the screen. If O\&W are correct, these manipulations should eliminate the space error and overconfidence.

\section{Method}

\section{Subjects}

Fifteen subjects ( 9 males, 6 females; mean age $=31$ years) partıcipated for one session of approximately 45 min duration in return for $\$ 7.78$ (Canadian) pay. All the subjects had normal or corrected- 

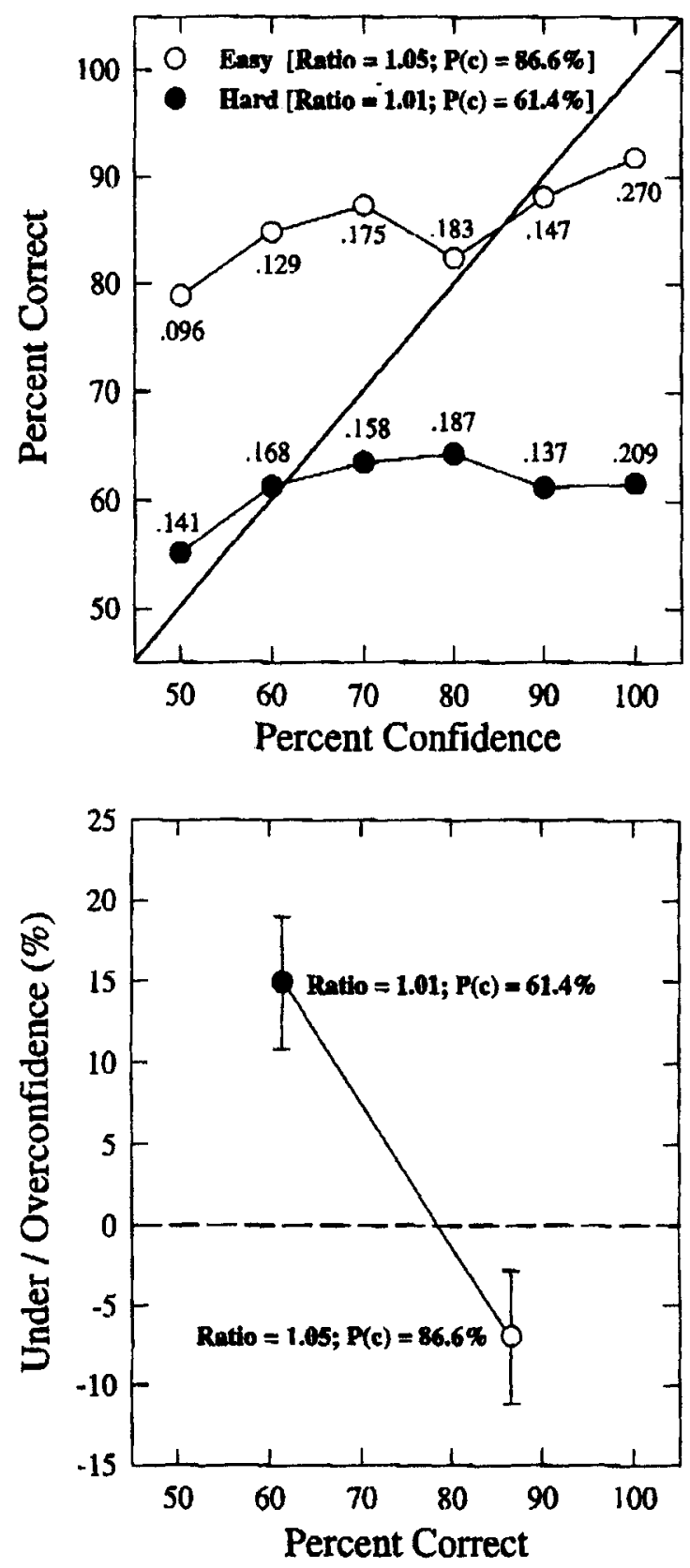

Figure 3. Top panel: Calibration curves for the hard and easy judgments. The proportion of times the various confidence categories were used is provided beside each data point. Bottom panel: hard-easy effect. Error bars denote the $S E M$ across subjects.

to-normal vision and were naive with respect to the nature and aims of the experiment.

\section{Apparatus and Stimuli}

The stimuli were presented on a Mrcroscan 4G/AD1 14-in. flat screen color monitor, which had a resolution capability of 480 pixels vertically $\times 640$ pixels horizontally. An IBM PC/386 computer controlled event sequencing, randomization, and the recording of responses, response times, and confidence reports. An IBM PC mouse was used as an input device.
On each trial, the stimulus display consisted of two lines that extended different lengths horizontally from the midpoint of a $10-\mathrm{mm}$ vertical, referent line. Eight pairs of horizontal lines were used in the experiment, and we define these eight pairs and their two presentation orders by the notation $(x, y)$, where $x$ denotes the length of the left line and $y$ denotes the length of the right line. The stimulus set, defined in pixels $(2.28$ pixels $=1 \mathrm{~mm})$, was 100,$101 ; 101,100$; 100,$105 ; 105,100 ; 150,152 ; 152,150 ; 150,157 ; 157,150 ; 200,202$; 202,$200 ; 200,210 ; 210,200 ; 250,253 ; 253,250 ; 250,262$; and 262,250 . Hence, for each of the four standards (i.e., 100, 150, 200, and 250 ), we defined two a prior levels of judgment difficulty on the basis of the ratio $(r)$ of the longer to the shorter extent (Münsterberg, 1894; Petrusic \& Jamieson, 1979) - hard judgments with $r \approx 1.01$, and easy judgments with $r \approx 1.05$. All the lines were $1 \mathrm{~mm}$ wide and appeared white on a black background.

The use of the edge of the monitor during the comparison task was precluded by a black partition made of heavy cardboard $(90 \mathrm{~cm}$ wide $\times 55 \mathrm{~cm}$ high, with a centered aperture measuring $26 \mathrm{~cm}$ wide $\times 19 \mathrm{~cm}$ high), which was attached to the circumference of the video monitor. Hence, in a completely darkened room, the partition provided a large, uniform black background for the line comparison task. The entire stımulus display, as it appeared on the screen, was adjusted horizontally so that the vertical referent coincided with the midpoint of the aperture. In addition, prior to each session, the lengths of the lines were measured on the screen, and the position of the central referent was verified, using Starrett (\#120) calipers.

\section{Design and Procedure}

Each trial began with the presentation of an instruction (LONGER or SHORTER) centered near the top of the screen, followed, $1.5 \mathrm{sec}$ later, by the stimulus pair. Both the instruction and the pair remained on the screen until the subject responded. The task required the subjects to determine which of the two horizontal lines was longer or shorter by depressing either the left or the right response button on the mouse. Following the response, the screen was cleared, and the subjects provided a confidence rating. The confidence scale consisted of six circular, confidence buttons (diameter $=3 \mathrm{~cm}$ ), which were displayed on the video screen and which were labeled $50,60,70,80,90$, and 100 , respectively. The buttons were arranged symmetrically on a semicircular arc, and adjacent buttons were separated by $1.5 \mathrm{~cm}$. To make a confidence report, the subjects used the mouse to move a visual pointer from a home mark to a confidence button ( $5.5 \mathrm{~cm}$, equidistant from each button) and then depressed a button on the mouse. A seventh button, labeled ERROR, was positioned $1.5 \mathrm{~cm}$ below the home mark and was to be used only on trials on which the subjects thought they made an error in the comparative judgment. In the written instructions that preceded each session, the subjects were briefly introduced to the notion of calibration, and it was explained that a confidence rating of $50 \%$ should denote a guess, or random choice, and that a confidence report of $100 \%$ should denote certainty in the correctness of their comparative judgment. The intermediate confidence reports, ranging from $60 \%$ to $90 \%$, should denote increasing certainty, in terms of a probability or likelihood, that the correct response had been selected. The subjects were given no instructions concerning the frequency with which the various confidence categories should be used, and there was no time limit for registering the confidence report. A 2-sec intertrial interval, with a blank screen, separated the confidence report and the ensuing tral.

Each session began with 32 practice trials (which were not analyzed). The practice trials were followed by five blocks of 64 experimental trials. The 64 trials in each block arose from the randomized factorial combination of the eight pairs, two presentation orders of each pair (e.g., 100,101;101,100), two instructions (LONGER or SHORTER), and two replicates. Thus, in all, 320 experimental trials were obtained from each of 15 subjects. 


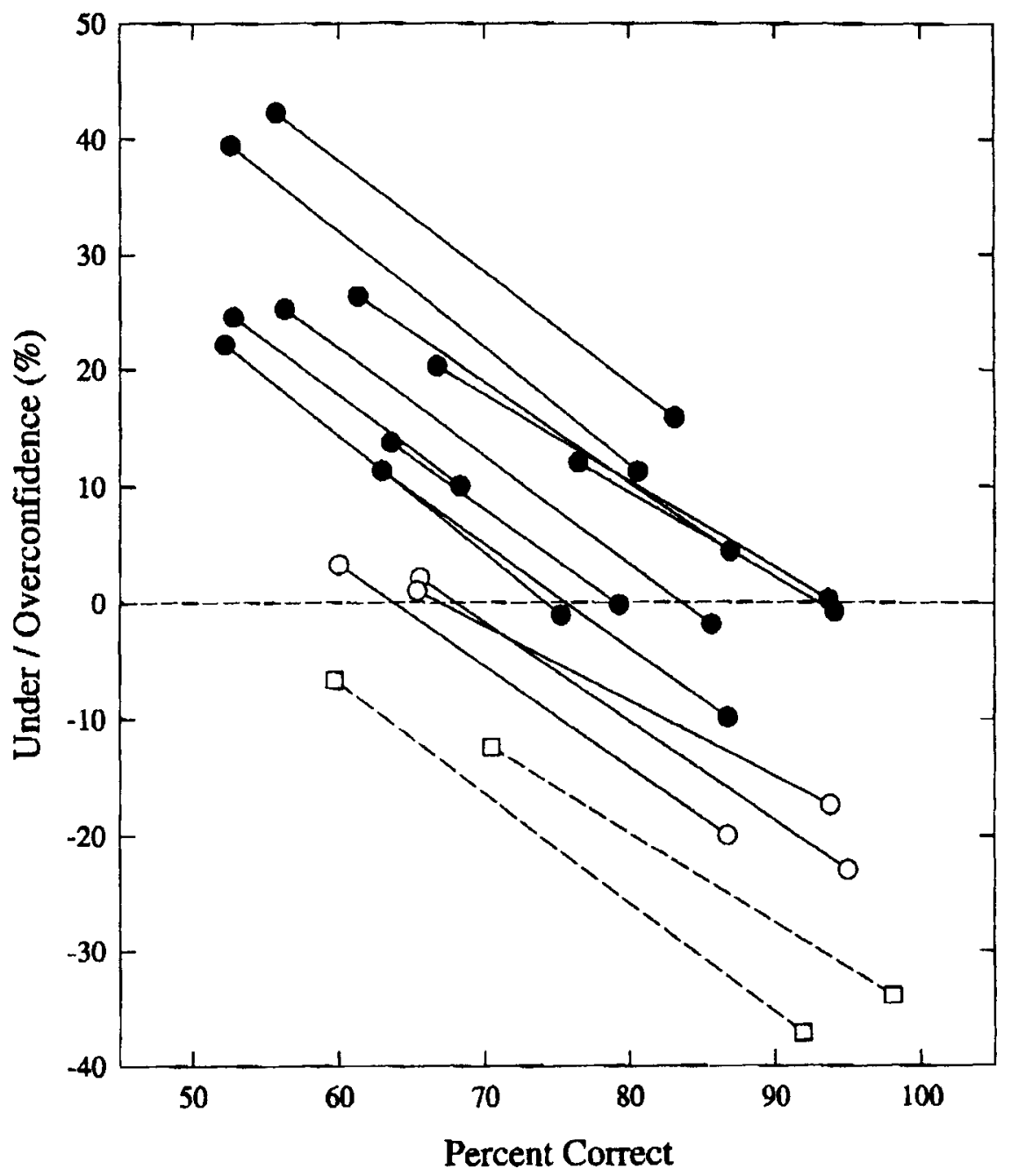

Figure 4. Hard-easy effects for each of the 15 subjects.

\section{Results}

Two types of trials were excluded from analyses: (1) trials on which response times exceeded $10 \mathrm{sec}$ or were less than $200 \mathrm{msec}(36 / 4,800 ; 0.8 \%)$ and $(2)$ trials on which the subjects did not provide a confidence rating because they thought they had made an error $(70 / 4,800 ; 1.4 \%)$.

\section{Calibration Analyses}

The top panel of Figure 3 provides calibration functions separately for the two levels of judgment difficulty; the proportion of times the various confidence levels were used is provided beside each point. As the figure shows, underconfidence is evident over most of the confidence scale for the easy judgments, whereas overconfidence is evident over most of the confidence scale for the hard judgments. A more concise depiction of the hard-easy effect is provided in the bottom panel of Figure 3. In replication of our previous studies, there is clear underconfidence for the easy judgments, clear overconfidence for the hard judgments, and a transition from under- to overconfidence in the $75 \%$ correct range. The effect of judgment difficulty (easy, hard) had a highly reliable effect on response accuracy $[86.6 \%$ vs. $61.4 \% ; F(1,14)=366.72, p<.0001]$, confidence $[79.7 \%$ vs. $76.4 \% ; F(1,14)=20.53, p<$ $.0005]$, and under/overconfidence [ $-6.94 \%$ vs. $14.93^{\circ} \%$; $F(1,14)=254.73, p<.0001]$ - the latter confirming a hard-easy effect with sensory discriminations. Finally, the under/overconfidence measure differed significantly from $0 \%$ in the direction of overconfidence for the hard discriminations $[t(13)=3.66, p<.003]$, confirming that overconfidence can be obtained with difficult (but still discriminable) sensory discriminations.

Figure 4 provides a plot of the under/overconfidence measure for the two levels (easy, hard) of judgment difficulty separately for each of the 15 subjects in the study. Two notable results are evident. First, a hard-easy effect is evident in the data of each of the 15 subjects. Second, we see rather striking individual differences in these plots (recall the historical quotes provided at the outset, and see Soll, 1996, for a view of large differences for in- 


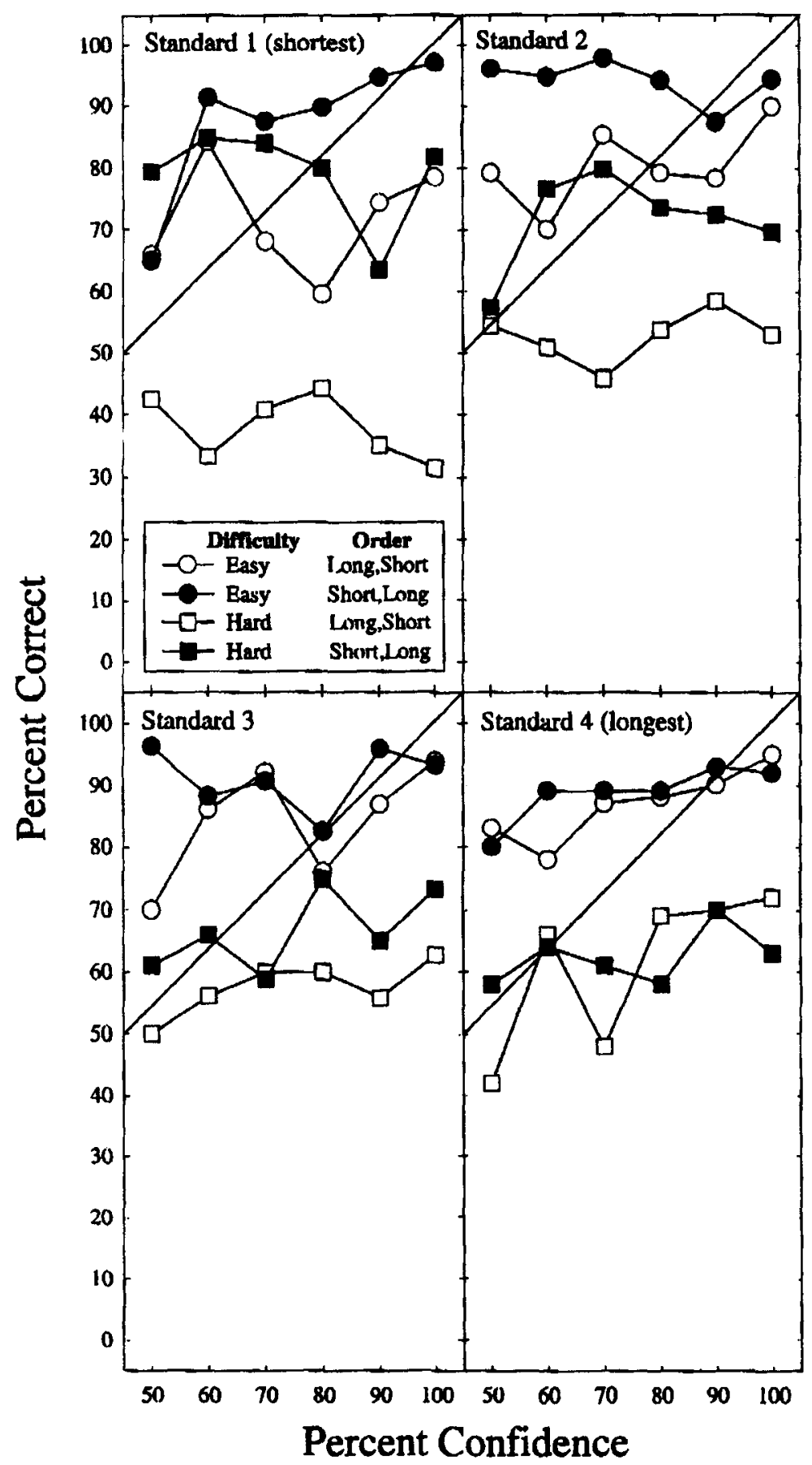

Figure 5. Calibration curves for the four standards, separately for the two presentation orders and the two levels of difficulty.

dividual subjects in the cognitive domain). Notably, 10 subjects show clear overconfidence with the difficult discriminations (filled circles), 3 subjects show a small overconfidence for the difficult discriminations (open circles), and 2 subjects are underconfident for both levels of difficulty (open squares). Importantly, the data for the 5 subjects shown in open symbols confirm that there were no general biases in the present judgmental task; otherwise, all the subjects would have been overconfident.

\section{Presentation Order Effects}

In our final analysis, we examine the effect of stimulus presentation order in the present study. Two results would be particularly informative. First, if space errors did 
Table 1

Percent Correct, Percent Confidence, and Percent Under/Overconfidence for the

Four Levels of Standard, Two Levels of Judgment Difficulty, and Two Presentation Orders

\begin{tabular}{|c|c|c|c|c|c|}
\hline $\begin{array}{l}\text { Standard } \\
\text { (Pixels) }\end{array}$ & $\begin{array}{c}\text { Difficulty } \\
\text { Level }\end{array}$ & $\begin{array}{c}\text { Presentation } \\
\text { Order } \\
\end{array}$ & $P(c)$ & Conf & $\mathrm{U} / \mathrm{O}$ \\
\hline \multirow[t]{4}{*}{100} & Easy & $\begin{array}{l}105,100(\mathrm{~L}, \mathrm{~S}) \\
100,105(\mathrm{~S}, \mathrm{~L})\end{array}$ & $\begin{array}{l}71.96 \\
90.85\end{array}$ & $\begin{array}{l}78.34 \\
82.61\end{array}$ & $\begin{array}{r}+6.39 \\
-8.24\end{array}$ \\
\hline & & $M$ & 81.46 & 80.49 & -0.97 \\
\hline & Hard & $\begin{array}{l}101,100(\mathrm{~L}, \mathrm{~S}) \\
100,105(\mathrm{~S}, \mathrm{~L})\end{array}$ & $\begin{array}{l}37.41 \\
78.69\end{array}$ & $\begin{array}{l}76.97 \\
77.69\end{array}$ & $\begin{array}{r}+39.56 \\
+1.00\end{array}$ \\
\hline & & $M$ & 58.03 & 77.23 & +19.20 \\
\hline \multirow[t]{4}{*}{150} & Easy & $\begin{array}{l}157,150(\mathrm{~L}, \mathrm{~S}) \\
150,157(\mathrm{~S}, \mathrm{~L})\end{array}$ & $\begin{array}{l}81.76 \\
93.75\end{array}$ & $\begin{array}{l}78.24 \\
80.10\end{array}$ & $\begin{array}{r}-3.51 \\
-13.65\end{array}$ \\
\hline & & $M$ & 87.89 & 79.23 & -8.66 \\
\hline & Hard & $\begin{array}{l}152,150(\mathrm{~L}, \mathrm{~S}) \\
150,152(\mathrm{~S}, \mathrm{~L})\end{array}$ & $\begin{array}{l}52.90 \\
71.92\end{array}$ & $\begin{array}{l}76.24 \\
77.12\end{array}$ & $\begin{array}{r}+23.34 \\
+5.20\end{array}$ \\
\hline & & $M$ & 62.42 & 76.47 & +14.06 \\
\hline \multirow[t]{4}{*}{200} & Easy & $\begin{array}{l}210,200(\mathrm{~L}, \mathrm{~S}) \\
200,210(\mathrm{~S}, \mathrm{~L})\end{array}$ & $\begin{array}{l}86.05 \\
90.81\end{array}$ & $\begin{array}{l}79.15 \\
79.73\end{array}$ & $\begin{array}{r}-6.90 \\
-11.09\end{array}$ \\
\hline & & $M$ & 88.39 & 79.37 & -9.03 \\
\hline & Hard & $\begin{array}{l}202,200(\mathrm{~L}, \mathrm{~S}) \\
200,202(\mathrm{~S}, \mathrm{~L})\end{array}$ & $\begin{array}{l}57.97 \\
67.23\end{array}$ & $\begin{array}{l}76.41 \\
76.72\end{array}$ & $\begin{array}{r}+18.44 \\
+9.49\end{array}$ \\
\hline & & $M$ & 62.34 & 76.56 & +14.22 \\
\hline \multirow[t]{4}{*}{250} & Easy & $\begin{array}{l}262,250(\text { L.S }) \\
250,262(\mathrm{~S}, \mathrm{~L})\end{array}$ & $\begin{array}{l}88.13 \\
89.79\end{array}$ & $\begin{array}{l}79.56 \\
79.59\end{array}$ & $\begin{array}{r}-8.58 \\
-10.20\end{array}$ \\
\hline & & $M$ & 88.88 & 79.50 & -9.38 \\
\hline & Hard & $\begin{array}{l}253,250 \\
250,253\end{array}$ & $\begin{array}{l}61.90 \\
63.44\end{array}$ & $\begin{array}{l}75.51 \\
74.48\end{array}$ & $\begin{array}{l}+13.61 \\
+11.03\end{array}$ \\
\hline & & $M$ & 62.71 & 75.10 & +12.39 \\
\hline
\end{tabular}

Note- $L$, long; S, short.

not occur, that would provide support for, and add generality to, the O\&W (1996) claim that measuring the stimuli on the screen, to ensure that they remained centered, and obscuring the edge of the monitor are sufficient to eliminate the space error. Of course, this would still leave our overconfidence data at odds with their findings and with the predictions of their sensory sampling model (Juslin \& Olsson, 1997). Second, if space errors did occur, that would provide evidence that the manipulations employed by $O \& W$ are not sufficient to eliminate the effect. In this case, we would have to confirm that the space error does not undermine our evidence for overconfidence in sensory discrimination (see Petrusic \& Baranski, 1997, for such an analysis with the near-far task).

Figure 5 provides calibration curves for the two stimulus presentation orders (long, short $=$ longer on the left, shorter on the right; short, long = shorter on the left, longer on the right), separately for the two levels of judgment difficulty (easy vs. hard) and the four levels of comparison standard $(100,150,200$, and 250$)$. The performance measures associated with these plots are provided in Table 1. Three important findings are evident in Figure 5 and Table 1. First, space errors are clearly evident in these data. More specifically, the effect is very large for Standard 1 and systematically declines with increasing standard length until, for the longest standard, it is completely absent. Note that for Standard 1, the effect of the space error on calibration for the hard judgments in the long,short order is similar to the findings reported earlier in our reanalysis of the Baranski and Petrusic (1994) data in the near-far task - that is, we see the negative calibration curve associated with a response accuracy that is below chance responding (37.41\%). Importantly, however, clear overconfidence is evident for the hard judgments in both presentation orders for Standards 2, 3, and 4 , where all configurations are discriminable and, in the latter case, there is no space error at all (see Table 1). Thus, in replication of Baranski and Petrusic (1994) and Petrusic and Baranski (1997), we conclude the following: (1) When the space error is very large (i.e., Standard 1), a massive overconfidence can be evident in the compromised order-similar to the effect of misleading (illusory or below chance) knowledge questions in the cognitive domain; (2) overconfidence is evident in both presentation orders when there is a small space error, but judgments are not illusory [i.e., $\mathrm{P}(\mathrm{c})>50 \%$; Standards 2 and 3]; and (3) overconfidence is clearly evident even when there is no space error at all (Standard 4).

Second, the direction of the space error for line length is opposite to the direction of the space error in the near-far task (Baranski \& Petrusic, 1994; Petrusic \& Baranski, 1997). Specifically, in the near-far task, accuracy was higher when the farther distance was on the left; with lines, accuracy was higher when the longer line was on the right. Under the assumption that subjects acquire the stimuli in a left-to-right fashion (Masin \& Agostini, 1991), the increased accuracy in the short,long presentation order in the present study is consistent with the typically observed negative time order error (TOE) for lines (Baranski \& Petrusic, 1992), whereby accuracy is higher when the longer of two lines is presented second (cf. Dawes, 1980, Experiment 5, for a view of the effects on calibration of the TOE in a duration discrimination task).

Finally, note that the space error in a particular presentation order is largely inconsequential to the level of under/overconfidence that is evident in the combined data. Specifically, in Table 1 (means), we provide summary statistics combined over the two presentation orders; the effect for calibration curve analyses is evident upon averaging the curves over the two presentation orders. In these analyses, it is important to note the striking similarity in the data for Standards 2, 3, and 4. Thus, only when space errors are very large (as with the far pairs in the near-far task or with Standard 1 in this study) will there be a small overall contribution to the level of overconfidence observed in an aggregated data set; the contribution will necessarily be small, because the large overconfidence in one presentation order is balanced by the large underconfidence in the other presentation order. Because of this symmetry property (i.e., more overconfidence in 
one order and less overconfidence in the other order), a clear interpretation of calibration data will be obtained in most situations, upon averaging the data over the two presentation orders.

An analysis of variance with Greenhouse -Geisser degrees of freedom (the degrees of freedom reported in the text are based on the design) was conducted, with the four levels of standard length $(100,150,200$, and 250$)$, the two levels of judgment difficulty (easy, hard), and the two levels of stimulus presentation order (long,short; short,long) as within-subjects factors. The dependent variables were (arcsine transformed) response accuracy, confidence, and under/overconfidence. The results were entirely consistent with the preceding discussion.

Response accuracy. The main effect of standard length $[F(3,42)=4.94, p<.008]$ was reliable; accuracy increased with standard length, confirming that judgments were sensitive to variations of stimulus differences with fixed ratios. The a priori effect of judgment difficulty (hard-easy) was, of course, highly reliable $[F(1,14)=$ $387.77, p<.0001]$. The main effect of presentation order was not reliable $(p>.1)$, but the important interaction between standard length and presentation order was significant $[F(3,42)=8.28, p<.008]$. The only other effect to approach significance was the three-way interaction between standard, difficulty (hard-easy), and order $[F(3,42)=2.96, p<.05$ with a conventional test, and $p=.066$ with the Greenhouse-Geisser degrees of freedom]. This interaction suggests that the presentation order effect was largest for the hard judgments made with the shortest standard.

Confidence. The only reliable effect was that of judgment difficulty $[F(1,14)=22.01, p<.0003]$. This suggests that subjects are largely unaware of the effects of presentation order, in terms of how it affects the subjective difficulty of the sensory discrimination.

Under/overconfidence. The results were very similar to those reported for response accuracy. The main effects of standard $[F(3,42)=5.05, p<.015]$ and judgment difficulty $[F(1,14)=263.05, p<.0001]$ were reliable. The effect of presentation order was not significant, but the interaction between standard and order was reliable $[F(3,42)=8.27, p<.007]$. Also, as with response accuracy, the three-way interaction between standard, judgment difficulty, and order approached significance $[F(3,42)=$ $3.23, p<.05$ with a conventional test, and $p=.057$ with the Greenhouse-Geisser degrees of freedom].

Individual subject analyses. Given that space errors occurred with these simultaneous line comparisons, it is natural to inquire about their basis. One possibility is that they reflect a general illusory aspect of judgment. However, this notion is contradicted by the fact that the space error was not uniform in direction and magnitude across subjects. Specifically, 6 subjects showed a clear space error that favored the short,long presentation order, 4 subjects showed a clear space error that favored the long,short presentation order, and the other 5 subjects showed either a very small space error that favored short,long or none at all. Given this pattern of individual-subject data, we conclude, contrary to O\&W (1996), that the space error is "real" and reflects idiosyncratic biases, either in responding (Link, 1992) or in perception (Hellström, 1985). It is clear that the magnitude and direction of the space error are task and stimulus dependent (e.g., lines vs. near-far) and that they are vulnerable to strategic experimental manipulation (Olsson \& Winman, 1996). As fascinating as they may be in their own right, however, they do not provide the basis for the clear overconfidence evident in the present study. Thus, in contrast to the data emanating from the Uppsala laboratory and the predictions of their sensory sampling model, we can find strong overconfidence in sensory discrimination under conditions in which subjects are not time pressured, judgments are not subject to large biases, and the comparative judgments in question are difficult but not impossible.

\section{GENERAL DISCUSSION}

O\&W (1996) claimed that the evidence for overconfidence presented by Baranski and Petrusic (1994, Experiment 2) arose as a consequence of an edge strategy on the part of our subjects, coupled with a misaligned computer screen. The first part of this paper presented a reanalysis of the presentation order effects in that study and showed that systematic manipulation of the stimulus display - a procedure that we commonly employ in the near-far task, precisely to discourage the use of the edge of the screen-will not affect the direction of the space error in the manner proposed and demonstrated by O\&W. We then provided evidence that replicated our previous findings of a robust hard-easy effect and clear overconfidence in a new task in which use of the edge of the screen monitor was precluded.

At this point, several questions need to be addressed: (1) What did O\&W (1996) really demonstrate in their experiments? (2) What is the nature of the difference in the empirical data emanating from our laboratories and the Uppsala laboratory?, and (3) What is the basis for this difference?

\section{The Olsson and Winman (1996) Findings}

In brief, O\&W (1996) were able to "replicate" our data by offsetting the stimulus display in a particular direction. This only proves that a pattern of data that mimics the space error can be obtained by such a manipulation, but it does not prove that we obtained the space error in that same way. Does this mean that the O\&W experiments are completely without merit? On the contrary, the experiments are informative in several respects.

First, O\&W's (1996) Experiment 1 provides a valuable replication of our previous finding that, when judgments are subject to biases or illusions, massive overconfidence can be obtained. Indeed, the monotone-decreasing calibration curves evident in O\&W and Baranski and Petrusic (1994) should, perhaps, be viewed as the signature of such a situation. Second, in O\&W's Experiment 2, it was 
predicted that precluding the use of the edge of the video monitor would reduce the proportion of correct responses (their Hypothesis 1, p. 380) and eliminate the space error (their Hypothesis 2, p. 380). Indeed, the difficult comparison pair $300,296(296,300)$ had an accuracy rate of $65 \%$ in their Experiment 1, but that same pair had an accuracy rate of $59 \%$ in their Experiment 2, and the space error was virtually eliminated. We believe that $O \& W$ overlooked a potentially important alternative explanation of these results -namely, that subjects' perceptions of the task can affect their judgments and confidence ratings. For example, O\&W state that "subjects have some prior expectation of task difficulty, implying that they do not believe that they will be given an impossible task" (p. 380). However, we propose that O\&W's data in their Experiment 2 strongly suggest that the majority of their subjects viewed their task as impossible--that is, not 1 subject used the certain category (i.e., $0 / 1,440$ trials), and the guess category was used on a remarkable $71.45 \%$ of the trials (i.e., 1,029/1,440 trials). With 12 subjects in their study, it is likely that several subjects used the guess category on every trial. Indeed, if a subject were to view the task as impossible and began responding randomly (e.g., responding left on each trial, or alternating between left and right from trial to trial), the proportion of correct response responses would diminish, and the space error would be eliminated.

\section{Is There a Fundamental Difference?}

With respect to the second question posed above, it is clear that we are able to observe overconfidence in sensory discrimination with far less difficulty than did the Uppsala laboratory. For example, in Baranski and Petrusic (1994), evidence for overconfidence was also demonstrated by a speed-accuracy tradeoff manipulation (which Juslin \& Olsson, 1997, recently cited in support of their theory) and in a gap detection experiment (Experiment 3 ), where an issue like the edge of the screen is not relevant because the entire display was only $6 \mathrm{~mm}$ square with 1-pixel (0.319-mm) gaps. More recently, Aubin and Petrusic (1997) provided additional evidence for robust hard-easy effects and overconfidence in a gap detection experiment in which the edge of the screen is irrelevant, and Baranski and Petrusic (1995) showed these effects in a task requiring point location judgments within unique Cartesian coordinate systems; again, the edge of the screen is irrelevant in such a task. As well, Oakley-McKeen and Petrusic (1997) demonstrated these effects in a variety of perceptual tasks (e.g., gap detection, area discrimination, and line length discrimination with visual masking).

Figure 6 provides a plot that summarizes the recent data from the two laboratories (Uppsala data are shown in the open symbols) on the hard-easy effect in sensory discrimination. In order to permit a direct comparison, we have included here only published studies involving visual discrimination tasks in which the subject (1) is not under time pressure and (2) controls the duration of the stimulus display (i.e., subject-controlled studies; see Vickers et al., 1985). Note that our results are quite consistent across studies and tasks, in that they show a transition from under- to overconfidence in the $75 \%$ correct range as accuracy decreases, which is consistent with the known transition point for cognitive judgment (see Suantak et al., 1996, for a meta-analysis of the hard-easy effect in sensory and cognitive tasks). Note also that the difference between the two labs is one of level, rather than of some fundamental qualitative discrepancy.

\section{Why a Difference?}

Given that the nature of the discrepancy between the laboratories is now evident, we turn to our third question, concerning the possible basis for the discrepancy. One obvious, albeit unremarkable, possibility is that it arises as a consequence of some as-of-yet undiscovered methodological factor (e.g., the selection of subjects who are not totally naive) or experimenter-induced bias (e.g., the manner in which instructions are delivered to the subjects). These matters can be easily resolved experimentally and may provide important insight into the factors that contribute to the numerical expression of confidence provided by observers.

The other, more intriguing possibility is that the difference between the laboratories is real and reflects an inherent cultural or national difference, so that Swedish (North American) subjects are generally more (less) conservative in their confidence judgments. Indeed, a review of the data from the two laboratories will show that our subjects use the certain category between $20 \%$ and $40 \%$, depending on the experiment and task. On the other hand, in many experiments, the Uppsala subjects never use the certain category. This underconfidence bias is so distinctive that it manifests itself even in supraliminal (i.e., virtually errorless) discrimination tasks. For example, in a recent paper by Juslin and Olsson (1997), their subjects had a mean confidence of only $75 \%$ and used the certain category but $13 \%$ of the time, for a level of judgment difficulty that was virtually errorless (i.e., $97 \%$ correct). Of course, the issue of cultural and national differences in probabilistic judgments is not unprecedented (see, e.g., Whitcomb, Önkal, Curley, \& Benson, 1995; Wright \& Phillips, 1980; Wright et al., 1978; Yates, Lee, \& Bush, 1997; Yates, Lee, \& Shinotsuka, 1996; Yates et al., 1989; Yeo \& Harvey, 1997), and if it is true that such a cultural difference exists in sensory discrimination tasks, contemporary theories of confidence and calibration will have to address the issue head-on (see Yates et al., 1996, for a discussion). Consistent with the hypothesis of a cultural difference between Swedish and North American subjects, one may recall Svenson's (1981) landmark study of U.S. versus Swedish drivers' self-estimates of their own driving competence. Svenson found, among other notable results, that $46.3 \%$ of U.S. drivers judged themselves in the top $20 \%$ of drivers, whereas only $15.5 \%$ of Swedish drivers did the same. 


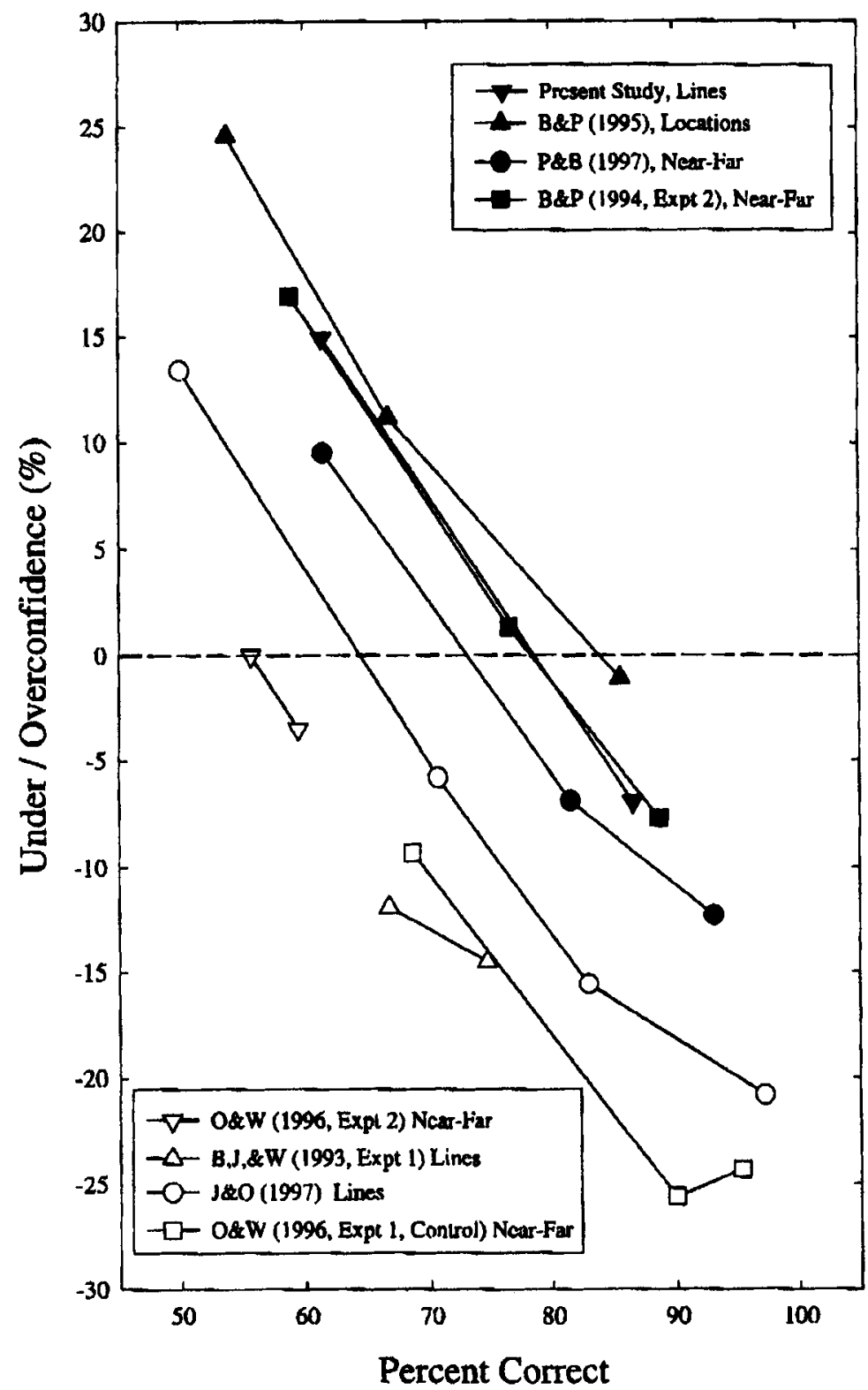

Figure 6. Hard-easy effects in visual discrimination tasks from the Petrusic and Baranski laboratories (filled symbols) and the Uppsala laboratory (open symbols).

\section{On the Underconfidence Bias in Sensory Discrimination}

Given the difficulty with which the Uppsala laboratory is able to observe overconfidence in their studies, it is perhaps understandable that they would speak of a pervasive underconfidence bias in sensory discrimination. We do not dispute that there are data that are consistent with this claim. For example, the Uppsala group has cited recent work by the Australian researchers Stankov and Crawford (1996) as providing data supportive of their position. Although it is true that data from the latter's five-alternative line judgment task show strong under- confidence when all judgment difficulty levels are averaged together, it is also true that clear overconfidence is evident when one looks separately at the more difficult levels of discrimination (see, e.g., Stankov, 1998). In addition, detailed and extensive individual-subject analyses have revealed that the same psychometric factor underlies overconfidence scores in perceptual and knowledge tasks (Stankov \& Crawford, 1996, p. 971).

The Uppsala group also cites the well-documented finding of greater than $50 \%$ correct responses associated with the guess category as evidence of an underconfidence bias in the early studies on confidence in psychophysics 
(e.g., Fullerton \& Cattell, 1892; Peirce \& Jastrow, 1884). In the first place, the phenomenon is not at all unique to the sensory domain and, thus, cannot be used to distinguish confidence in the sensory and the cognitive domainsthat is, at or above $60 \%$ correct when guessing is clearly evident in many contemporary calibration studies involving cognitive judgments (e.g., Griffin \& Tversky, 1992; Juslin, 1993, 1994; Juslin et al., 1997; Lichtenstein \& Fischhoff, 1977, to name just a few of many such studies). Second, several classic data sets show clear evidence of overconfidence. For example, in Henmon's (1911) line length comparison study, Henmon's 7 subjects (A-G) were correct only $80 \%$ of the time that they were certain, and they used the certain category over $50 \%$ of the time. Also, Garrett's (1922) classic data on confidence in lifted weights showed his subjects to be $86 \%$ correct when certain, and again, the certain category was used very often $(>30 \%)$. More generally, in many classic studies in psychophysics, subjects were as overconfident when certain as they were underconfident when guessing. A more modern depiction of these general tendencies is evident in the top panel of Figure 3, upon averaging the two calibration curves. The phenomena arise as a consequence of generally poor resolution in sensory discrimination tasks (informally, resolution is an index of the ability to distinguish correct from incorrect responses; see Baranski \& Petrusic, 1994; Björkman, 1994; Yates, 1990).

Finally, it is important to note that the hard-easy effect and overconfidence in contemporary calibration research on sensory discrimination is a finding not peculiar to our laboratories in Ottawa and Toronto. Stratigakos (1994), working in William Ferrell's laboratory at the University of Arizona, found large hard-easy effects and clear overconfidence in a line comparison task, and more recently, Ariely, Zauberman, and Wallsten (19.95) reported similar results in their experiments at the University of North Carolina at Chapel Hill. Outside of North America, McClelland, Bolger, and Tonks (1992), from University College in London, found both hard-easy effects and overconfidence in a visual judgment task requiring the detection of change. In addition, Skotnikova (1994), from the Russian Academy of Sciences in Moscow, interpreted her results from a difficult visual duration discrimination experiment as clear evidence of overconfidence in sensory discrimination. Hence, contrary to the data and assertions emanating from the Uppsala laboratory, we believe that the evidence for an underconfidence bias in sensory discrimination is neither pervasive nor universal.

\section{Conclusion}

The present paper has focused, to a large degree, on the issue of whether overconfidence can be obtained in sensory discrimination. This is an admittedly narrow preoccupation; however, it was forced upon us by the $\mathrm{O} \& \mathrm{~W}$ (1996) critique. In fact, our position has always been that because people can be both over- and underconfident in both cognitive and sensory tasks, it is as problematic to speak of a general overconfidence bias in cognitive tasks as it is problematic to speak of a general underconfidence bias in sensory tasks. Moreover, it is perhaps futile to debate a few percentage points difference in where, along the accuracy continuum, the hard-easy effect changes from under- to overconfidence in sensory versus cognitive tasks. For example, in some studies, cognitive tasks will show slightly more overconfidence (Keren, 1988), perhaps because of a greater proportion of illusory (misleading) knowledge questions, whereas in other studies, perceptual tasks will show slightly more overconfidence (Baranski \& Petrusic, 1995), perhaps because of a greater proportion of illusory (below chance) perceptual judgments. The critical point is that hard-easy effects occur in both domains and, thus, theories that predict exclusively underconfidence (Björkman et al., 1993; Winman \& Juslin, 1993) or exclusively overconfidence (see McClelland \& Bolger, 1994, for a review of these theories) are not supported. Indeed, underlying the hard-easy effect are two opposing yet fascinating facts about human judgment: People are more often right than wrong when they guess (a general form of underconfidence, forcefully noted by Peirce \& Jastrow, 1884), and people are not always correct when they are certain (a general form of overconfidence, forcefully noted by Titchener, 1905). Between these two extremes, at approximately $75 \%$ correct responses, we are most likely to observe realism in confidence judgments.

Given that the hard-easy effect occurs in both the cognitive and the sensory domains and that it is not exclusively a consequence of regression to the mean, the question remains as to whether the result is best described by distinct theories that produce the same effect through fundamentally different mechanisms or by a single, general theory that is applicable in the two domains. Our perspective is that the similar pattern of hard-easy effect in both domains is a necessary, although not sufficient, condition for considering a general theoretical perspective of confidence in human judgment. However, when we add to this result the fact that the properties of decision times in cognitive tasks mirror those observed in sensory tasks (see, e.g., Baranski \& Petrusic, 1995; Wright \& Ayton, 1988), the argument should become more compelling. In particular, the latter result implicates a common decision process in sensory and cognitive tasks or, at the very least, decision processes with highly similar properties. To date, the only theories that have provided a basis for explicating the relations among decision time, confidence, and response accuracy in the sensory domain have been those based on stochastic evidence accrual processes (e.g., Audley, 1960; Baranski \& Petrusic, 1991, 1996; Juslin \& Olsson, 1997; Link, 1992; Petrusic \& Baranski, 1997; Vickers, 1979; Vickers et al., 1985). The question of whether these theories are applicable to confidence calibration in the cognitive domain should now take center stage. 


\section{REFERENCES}

Ariely, D., Zalberman, G., \& Wallsten, T. (1995, August). Statistical and psychological considerations in calibration research: Overconfidence, the hard-easy effect, and the influence of response scale on judgment. Paper presented at SPUDM-15, Jerusalem, Israel

Aubin, P., \& Petrusic, W. M. (1997, November). Overconfidence in sensory detection. Abstracts of the Psychonomic Society, 2, 61 .

AUDLEY, R. J (1960). A stochastic model for individual choice behavior. Psychological Review, 67, 1-15.

Baranski, J. V., \& Petrusic, W. M (1988), Calibration of perceptual judgments [Abstract]. Canadian Psychology, 29, 35.

BaRANSKI, J. V., \& Petrusic, W. M. (1991). Confidence calibration and the scaling of doubt [Abstract]. Canadian Psychology, 32, 369.

Baranski, J. V., \& Petrusic, W. M. (1992). The discriminability of remembered magnitudes. Memory \& Cognition, 20, 254-270.

Baranski, J. V., \& Petrusic, W. M. (1994). The calibration and resolution of confidence in perceptual judgments. Perception \& Psychophysics, 55, 412-428.

Baranski, J. V., \& Petrusic, W. M. (1995). On the calibration of knowledge and perception. Canadian Journal of Experimental Psychology, 49, 397-407.

Baranski, J. V., \& Petrusic, W. M. (1996). A doubt-scaling model of confidence calibration in human judgment [Abstract]. International Journal of Psychology, 31, 186.

Baranski, J. V., \& Petrusic, W. M. (1998). Probing the locus of confidence judgments: Experıments on the tıme to determine confidence. Journal of Experimental Psychology: Human Perception \& Performance, 24, 929-945.

BuörKMAN, M. (1994). Internal cue theory: Calibration and resolution of confidence in general knowledge. Organizational Behavior \& Human Decision Processes, 58, 386-405.

Buörkman, M., JusLin, P., \& Winman, A. (1993). Realism of confidence in sensory discrimination: The underconfidence phenomenon. Perception \& Psychophysics, 54, 75-81.

Budescu, D. V., Wallsten, T. S., \& Au, W. T. (1997). On the importance of random error in the study of probability judgment: II. Applying the stochastic judgment model to detect systematic trends. Journal of Behavioral Decision Making, 10, 173-188.

DAWEs, R. M. (1980). Confidence in intellectual vs. confidence in perceptual judgments. In E. D. Lantermann \& H. Feger (Eds.), Similarity and choice Papers in honor of Clyde Coombs (pp. 327-345). Bern: Hans Huber.

Dawes, R. M., \& Mulford, M. (1996). The false consensus effect and overconfidence: Flaws in judgment or flaws in how we study judgment? Organizational Behavior \& Human Decision Processes, 65, 201-211.

Erev, I., Wallsten, T. S., \& Budescu, D. V. (1994). Simultaneous over- and underconfidence: The role of error in judgment processes. Psychological Review, 101, 519-527.

FECHNER, G. T. (1966). Elements of psychophysics (Vol. 1; H. E. Adler, Trans.). New York: Holt. (Original work published 1860)

FERRELL, W. R. (1994). Calibration of sensory and cognitive judgments: A single model for both. Scandinavian Journal of Psychology, 35, 297-314.

FERRELL, W. R. (1995), A model for realism of confidence judgments: Implications for underconfidence in sensory discrimination. Perception \& Psychophysics, 57, 246-254.

FerrelL, W. R., \& MCGoey, P. J. (1980). A model of calibration for subjective probabilitıes. Organizational Behavior \& Human Performance, 26, 32-53.

FEstinger, L. (1943). Studies in decision: I. Decision time, relative frequency of judgment and subjective confidence as related to physical stimulus difference. Journal of Experimental Psychology, 32, 291306.

Fullerton, G. S., \& CATTELL, J. M. (1892). On the perception of small differences (University of Pennsylvania Philosophy Series, No. 2). Philadelphia: University of Pennsylvania.

GarRetT, H. E. (1922). A study of the relation of accuracy to speed. Archives of Psychology, 56, 1-104.

Gigerenzer, G., Hoffrage, U., \& Kleinbölting, H. (1991). Probabilistic mental models: A Brunswikian theory of confidence Psychological Review, 98, 506-528.
Griffin, D. W., \& TVERSKY, A. (1992). The weighing of evidence and the determinants of confidence. Cognitive Psychology, 24, $411-435$. GRIFFING, J. H. (1895). On sensations from pressure and impact. Psychological Review Monographs, 1, 1-88.

HaRvey, N. (1994). Relations between confidence and skilled performance. In G. Wright \& P Ayton (Eds.), Subjective probability (pp. 321-352). Chichester, U.K.: Wiley.

Harvey, N. (1997). Confidence in judgment. Trends in Cognitive Sciences, $1,78-82$.

HEATH, R. A. (1985). Random-walk and accumulator models of psychophysical discrimination: A critical evaluation. Perception, 13, 5765 .

HELLSTRÖM, Å. (1985). The tıme-order error and its relatives: Mırrors of cognitive processes in comparing. Psychological Bulletin, 97, 3561.

Henmon, V. A. C. (1911). The relation of the time of a judgment to its accuracy. Psychological Review, 18, 186-201.

Jamieson, D. G., \& Petrusic, W. M. (1975). Presentation order effects in duration discrimination. Perception \& Psychophysics, 17, 197202.

Johnson, D. M. (1939). Confidence and speed in the two-category judgment. Archives of Psychology, 241, 1-51.

JusLin, P. (1993). An explanation of the hard easy effect in studies of realism of confidence in one's general knowledge European Journal of Cognitive Psychology, 5, 55-71.

JusilN, P. (1994). The overconfidence phenomenon as a consequence of informal experimenter-guided selection of almanac items. Organizational Behavior \& Human Performance, 57, 226-246.

Juslin, P., \& Olsson, H. (1996, November). Thurstonian and Brunswikian origins of uncertainty in judgment. A sampling model of confidence in sensory discrimination. Paper presented at the Annual Meeting of the Society for Judgment and Decision Making, Chicago.

Juslin, P., \& Olsson, H. (1997). Thurstonian and Brunswikian origins of uncertainty in judgment: A sampling model of confidence in sensory discrimination. Psychological Review, 104, 344-366.

Juslin, P., Olsson, H., \& Bjökman, M. (1997). Brunswikıan and Thurstonian origins of bias in probability assessment On the interpretation of stochastic components of judgment. Journal of Behavioral Decision Making, 10, 189-209.

KerEN, G. (1988). On the ability of monitoring non-veridical perceptions and uncertain knowledge: Some calibration studies. Acta Psychologica, 67, 95-119.

Keren, G. (1991). Calibration and probability judgments: Conceptual and methodological issues. Acta Psychologica, 77, 217-273

Lichtenstein, S., \& Fischroff, B. (1977). Do those who know more also know more about how much they know? The calibration of probability judgments. Organizational Behavior \& Human Performance, 20, 159-183.

Lichtenstein, S., Fischhoff, B., \& Phillips, L. D. (1982). Calibration of probabilities: The state of the art to 1980 . In D. Kahneman, P. Slovic, \& A. Tversky (Eds.), Judgment under uncertainty: Heuristics and biases (pp. 306-334). Cambridge: Cambridge Lniversity Press.

LiNK, S. W. (1992). The wave theory of difference and similarity. Hillsdale, NJ: Erlbaum.

Masin, S. C., \& AGostini, A. (1991). Attentional scanning and space errors. Perception \& Psychophysics, 50, 285-289.

MAY, R. S. (1986). Inferences, subjective probability and frequency of correct answers: A cognitive approach to the overconfidence phenomenon. In B. Brehmer, H. Jungermann, \& G. Sevon (Eds.), New directions in research on decision making (pp. 175-189). Amsterdam: Elsevier.

MCClelland, A. G. R., \& Bolger, F. (1994). The calibration of subjectıve probabilities: Theories and models, 1980-1994. In G. Wright \& P. Ayton (Eds.), Subjective probability (pp. 453-482). Chıchester, U.K.: Wiley.

MCClelland, A. G. R., Bolger, F., \& Tonks, E. (1992, November) Calibration of probabilities in a perceptual discrimination task. Paper presented at the Annual Meeting of the Society for Judgment and Decision Makıng, St. Louis.

MünSTERBERG, H. (1889). Beiträge zur experimenteller Psychologie [Contributions to experımental psychology]. Freiberg: J. C. B. Mohr 
MünsterberG, H. (1894). Studies from the Harvard psychological laboratory A psychometric investigation of the psychophysic law. Psychological Review, 1, 45-51.

Oakl.ey-McKeen, K. J., \& Petrusic, W. M. (1997, August). Task and age-enhanced difficulty effects of confidence in judgment and decision making Support for the generality of the effect. Paper presented at the World Congress on Gerontology, Adelaide, Australia.

Olsson, H., \& WinMan, A. (1996). Underconfidence in sensory discrimınation. The interaction between experimental setting and response strategies. Perception \& Psychophysics, 58, 374-382.

Peirce, C. S., \& Jastrow, J. (1884). On small differences of sensation. Memoirs of the National Academv of Sciences, 3, 75-83.

Petrusic, W. M. (1992). Semantic congruity effects and theories of the comparison process. Journal of Experimental Psychology. Human Perception \& Performance, 18, 962-986.

Petrusic, W. M., \& Baranski, J. V. (1989a). Context, context shifts, and semantic congruity effect in comparative judgments. In D. Vickers \& P. Smith (Eds.), Human information processing. Measures, mechanisms, and models (pp. 231-251). Amsterdam: North-Holland.

Petrusic, W. M., \& Baranski, J. V. (1989b). Semantic congruity effects in perceptual comparisons. Perception \& Psychophysics, 45, 439-452

Petrlisic, W. M., \& Baranski, J. V. (1997). Context, feedback, and the calibration and resolution of confidence in perceptual judgments. American Journal of Psychology, 110, 543-572.

Petrlisic, W. M., \& Jamieson, D. G. (1979). Resolution time and the coding of arithmetic relations on supralıminally different visual extents. Journal of Mathematical Psychology, 19, 89-107.

SC HAB, F. R.. \& CrowDER, R. G. (1988). The role of succession in temporal cognition: Is the time-order error a recency effect of memory? Perception \& Psvchophysics, 44, 233-242.

Skotnikova, I. (1994). Accuracy, confidence-unconfidence and response tıme in unordered discrimınation: Subject-oriented research. In L. Ward (Ed.), Fechner Dav '94 Proceedings of the 10th Annual Meeting of the International Society for Psychophysics (pp. 208 213). Vancouver: International Society for Psychophysics.

SOL.L., J. B ( 1996). Determinants of overconfidence and miscalibration: The roles of random error and ecological structure. Organizational Behavior \& Human Decision Processes, 65, 117-137.

Stankov, L. (1998). Calıbration curves, scatterplots and the distınction between general knowledge and perceptual tasks. Learning \& Individual Differences, 10, 29-50.

Stankov, L., \& Crawford, J. D. (1996). Confidence judgments in studies of individual differences. Personalitv \& Individual Differences, 21, 971-986.

Stratigakos, S. (1994). Sensory calibration: An investigation into the existence of the hard-easv effect. Unpublished data. University of Arızona, Systems and Industrial Engineering Department.

Suantak, L., Bolger, F, \& Ferrell, W. R. (1996). The hard-easy effect in subjective probability calibration. Organizational Behaviour \& Human Decision Processes, 67, 201-221.

SVENSON, O (1981). Are we all less risky and more skillful than our fellow drivers? Acta Psychologica, 47, 143-148.

TiTCHENER, E. B. (1905). Experimental psychology Quantitative students manual. New York: Macmillan.

Trow, W. C. (1923). The psychology of confidence. Archives of Psychology, 67, 1-47

VICKERS, D. (1979). Decision processes, in visual perception. New York: Academic Press.

ViCKeRS, D., \& PACKer, J. (1982). Effects of alternating set for speed versus accuracy on response tıme, accuracy, and confidence in a unidimensıonal discrimination task. Acta Psychologica, 50, 179-197.

Vickers, D., SMITH, P, Burt, J., \& Brown, M. (1985). Experimental paradigms emphasizing state or process limitations: II. Effects on confidence. Acta Psychologica, 59, 163-193.

Wallsten, T. S., \& Budescu, D. V. (1983). Encoding subjective probabilitıes: A psychological and psychometric review. Management Science, 29, 152-173.

Whitcomb, K. M., Önkal, D., Curley, S., \& Benson, P. G. (1995). Probability judgment accuracy for general knowledge: Cross- national differences and assessment methods. Journal of Behavioral Decision Making, 8, 51-67.

WinMAN, A., \& JuSLIN, P. (1993). Calibration of sensory and cognitive judgments: Two different accounts. Scandinavian Journal of Psychology, 34, 135-148.

Wright, G. [N.], \& Ayton, P. (1988). Decision time, subjective probability, and task difficulty. Memory \& Cognition, 16, 176-185.

Wright, G. N., \& Phil.tips, L. D. (1980). Cultural variation in probabilistic thinking: Alternative ways of dealing with uncertainty. International Journal of Psychology, 15, 239-257.

Wright, G. N., Phillips, L. D., Whalley, P. C., Choo, G. T., Ng, K. O., TAN, I., \& Wisudha, A. (1978). Cultural differences in probabilistic thinking. Journal of Cross-Cultural Psychology, 9, 285-299.

YATES, J. F. (1990). Judgment and decision making. Englewood Cliffs, NJ: Prentice-Hall.

YATES, J. F., LEE, J., \& BuSH, J. (1997). General knowledge overconfidence: Cross-national variations, response style, and "reality." Organizational Behavior \& Human Decision Processes, 70, 87-94.

YATES, J. F., LEE, J., \& SHinotsuKa, H. (1996). Belıefs about overconfidence, including its cross-national variation. Organizational Behavior \& Human Decision Processes, 65, 138-147.

Yates, J. F., Zhu, Y., Ronis, D. L., Wang, D.-F., Shinotsuka, H., \& TODA, M. (1989). Probability judgment accuracy: China, Japan, and the United States. Organizational Behaviour \& Human Decision Processes, 43, 145-171.

Yeo, S. B., \& HaRvey, N. (1997, August). Effects of cultural background and education type on probability judgment. Paper presented at SPUDM 16, Leeds, U.K.

\section{NOTES}

1. Several authors have noted that the hard-easy effect can arise because of random error in the judgment process (e.g., Erev, Wallsten, \& Budescu, 1994; Juslın, Olsson, \& Björkman, 1997) or, more generally, regression effects based on a less-than-perfect correlation between confidence and accuracy (e.g., Dawes \& Mulford, 1996). For the present paper, we are less concerned with the hard-easy effect per se than with the occurrence of overconfidence, which is not a necessary consequence of the hard-easy effect (i.e., other factors regulate it as well). In addition, Budescu, Wallsten, and Au (1997) have shown that a pure index of overconfidence can be obtained after removing the effects of random error.

2. Fechner (1860/1966, p. 73) documented two general classes of presentation order effect, depending on whether the stimuli to be compared were presented successively or simultaneously. His general designation for these presentation order effects was that of a constant error (CE) in judgment. CEs that occur in tasks in which the stimuli are separated in time and space are now commonly referred to as time order errors (for recent reviews, see Baranski \& Petrusic, 1992; Hellström, 1985; Jamieson \& Petrusic, 1975; Schab \& Crowder, 1988) and space errors (for a review, see Masin \& Agostini, 1991), respectively. When the method of constant stimuli is used, the $C E$ is indexed by the difference between the standard and the point of subjective equality. When a roving standard design is used (as in the present study), the CE is indexed by the difference in discriminative performance between one order of stımulus presentation (e.g., 101,100) and the other (e.g., 100,101, where the two numbers refer, for example, to the lengths of two lines, one on the left of the display and the other on the right). In one of the earliest statements on the space error, Garrett (1922) reviews Münsterberg's (1889) classic experiments on horizontal extent and comments on the finding that "distances to the left are usually overestimated, to the right underestimated, due probably to habits formed in reading and writing from left to right" (p. 14; see Masin \& Agostini, 1991, for corroborating data and a contemporary discussion). Interestingly, Garrett (1922, p. 65) confirms this effect in his own experıments on visual extent, but Henmon (1911, p. 195) finds the space error to go in the opposite direction, suggesting that the phenomenon may be due, in part, to idiosyncratic (response) biases in judgment.

(Manuscript received September 18, 1997; revision accepted for publication July 14, 1998.) 